\title{
Landslide Displacement Prediction Affected by the Periodic Precipitation, Reservoir Level and Groundwater Level Fluctuations
}

\author{
$\mathrm{Fu} \operatorname{Ren}^{1}$ and Xueling $\mathrm{Wu}^{2, *}$ \\ ${ }^{1}$ School of Resource and Environmental Sciences, Wuhan University, Wuhan, \\ 430079, China \\ ${ }^{2}$ Institute of Geophysics and Geomatics, China University of Geosciences, Wuhan, \\ 430074, China \\ *snowforesting@163.com
}

\begin{abstract}
Since the initial impoundment of the Three Gorges Reservoir in June 2003 and approximately $30 \mathrm{~m}$ of reservoir level fluctuation, numerous preexisting landslides have been reactivated. To mitigate disastrous landslides, the Baishuihe landslide in the Three Gorges region was selected as a case study in predicting such displacement using the monitoring dataand a radial basis function-support vector machine (RBF-SVM) model.The landslide displacement was strongly influenced by periodic precipitation, reservoir level and groundwater level fluctuations. Primary landslide influencing factors were used as independent variables to predict the displacement using several kernel function types including sigmoid function, polynomial function, and RBF based on SVM model.Prediction results demonstrated that the RBF-SVM with the optimal parameters ${ }_{c}, \varepsilon$ and $\gamma$ of $170,0.05$ and 0.04 can provide the best predictive accuracy, with the maximum and minimum absolute error values of 9.84 and $0.47 \mathrm{~mm}$, respectively.
\end{abstract}

Keywords: Landslides, Displacement prediction, Support vector machine (SVM), Three Gorges

\section{Introduction}

Landslides are a major natural geological hazard in the Three Gorges Reservoir area threating the normal operation of the Three Gorges Dam and even causing damage to both property and lives [1].Especially the high reservoir impoundment of the Three Gorges Reservoir beginning in June 2003, the frequency and magnitude of landslides are expected to increase with the reactivation of old landslides and triggering of new ones. Old landslides began to noticeably deform, including the Baishuihe landslide, Baijiabao landslide, and Shiliushubao landslide [2,3]. These landslides are primarily located along the Yangtze River and its tributaries, and their deformation characteristics are closely associated with the seasonal precipitation, reservoir level and groundwater level fluctuations. Statistics indicate that approximately 2,490 landslides are present in the Three Gorges region and that 200 landslides occur each year[4].The potential risk posed by these landslides is substantial. The extent of potential disastersmay be minimized by understanding their mechanisms and developing predictions, hazard assessments, early warning systems, and risk management of the landslides. Predicting the displacement of an active landslide is of great importance in preventing

\footnotetext{
* Corresponding Author
} 
landslidesand reducingtheir occurrence in the Three GorgesReservoir area. To achieve this objective, a landslide displacement prediction was applied to the Baishuihe landslideusing a radial basis function-support vector machine (RBF-SVM) model and 5 years of monitoring data.

In recent years, different approaches have been carried out on displacement prediction of landslides. Li et al. in [5] summarized many landslide deformation prediction studies, which can be grouped into three categories: deterministic, statistical, and computational intelligence methods. Deterministic models are primarily applied for physical mechanisms of the rock and soil mass and can provide a clear physical explanation [6], but they requirecomprehensive data of the material parameters. Statistical models have been widely used in deformation prediction of landslides.The results of such models are relatively easy to explain [7], but they are inherentlylinear and lack data from complex landslide systems. Intelligent methods have recently been widely applied for mining patterns by identifying the underlying rules and features in a nonlinear landslide system, including artificial neural networks (ANNs) and SVMs. The ANN model can be used to identify the complex nonlinear relationships between landslide displacement and the major conditioningfactors [8-10], although it is prone to over fitting. SVM model is becoming increasingly popular, as it offers one of the most robust and accurate methods among well-known algorithms and ranks among the top 3 data-mining algorithms identified by the IEEE [11]. The method is also well suited to nonlinear high-dimensional data modeling problems and shows promise in predictinglandslide displacement $[12,13]$. Micheletti et al. in [14] concluded that SVM models can be used effectively in landslide studies due to their capability in dealing with high-dimensional spaces. Min and Lee in [15] stated that a search for optimal parametersinan SVM model plays a crucial role in building a landslide prediction model. To develop an efficient SVM model, kernel functions and the corresponding parameters must be carefully predetermined [16-18].

Landslide deformation in the Three Gorges Reservoir area is often closely related to seasonal precipitation, reservoir level and groundwater level fluctuations. In this paper, the Baishuihe landslide was selected as a typical rocky landslide in the Three GorgesReservoir area for analyzing the relationships between the displacement and the primary influencing factors. A RBF-SVM model was adopted to predict the displacement using six primary driving factors as predictor variables, including the cumulative precipitation during the current month, maximum daily precipitation during the current month, average reservoir level during the current month, cumulative increments and decrements in the reservoir level during the current month, average groundwater level during the current month, and cumulative incrementsand decrements inthe groundwater level during the current month. Finally, the prediction results were validated by comparing it with the known observed displacement.

\section{Description of the Baishuihe Landslide}

The Baishuihe landslide, which is a large, active ancient landslide, occurred on the south bank of the Yangtze River $\left(31^{\circ} 01^{\prime} 34^{\prime \prime} \mathrm{N}, 110^{\circ} 32^{\prime} 09^{\prime \prime} \mathrm{E}\right)$, in the village of Baishuihe, Shazhenxi Town, Zigui County, Hubei Province, China. The landslide is approximately $56 \mathrm{~km}$ west of the Three Gorges Dam (Figure 1). The bedrock geology of this landslide is mainly composed of sandstone and mudstone, which is an easy slip stratum. The slope is of the category ofbedding slopes, and borehole monitoring data indicatethat 
average thickness of the landslide is about $30 \mathrm{~m}$. The landslide lies at an elevation of 75 to $390 \mathrm{~m}$. The landslide covers an area of approximately $0.42 \mathrm{~km}^{2}$ and has an estimated volume of $1,260 \times 10^{4} \mathrm{~m}^{3}$ and maximum length of approximately $780 \mathrm{~m}$. The transverse width is approximately $700 \mathrm{~m}$ parallel tothe Yangtze River. The Baishuihe landslide was reactivated after the initial impoundment of the Three Gorges Reservoir. The fluctuation of the reservoir level was a crucial influencing factor in therecent landslide displacement. The 5yearsof monitoring data between January 2004 and May 2008 indicate that the seasonal precipitation and groundwater level fluctuation are also significant factors in the landslide deformation. Superficial cracking and distinct ground displacements were observed on the ground, asshown in Figure 2 and Figure 3.
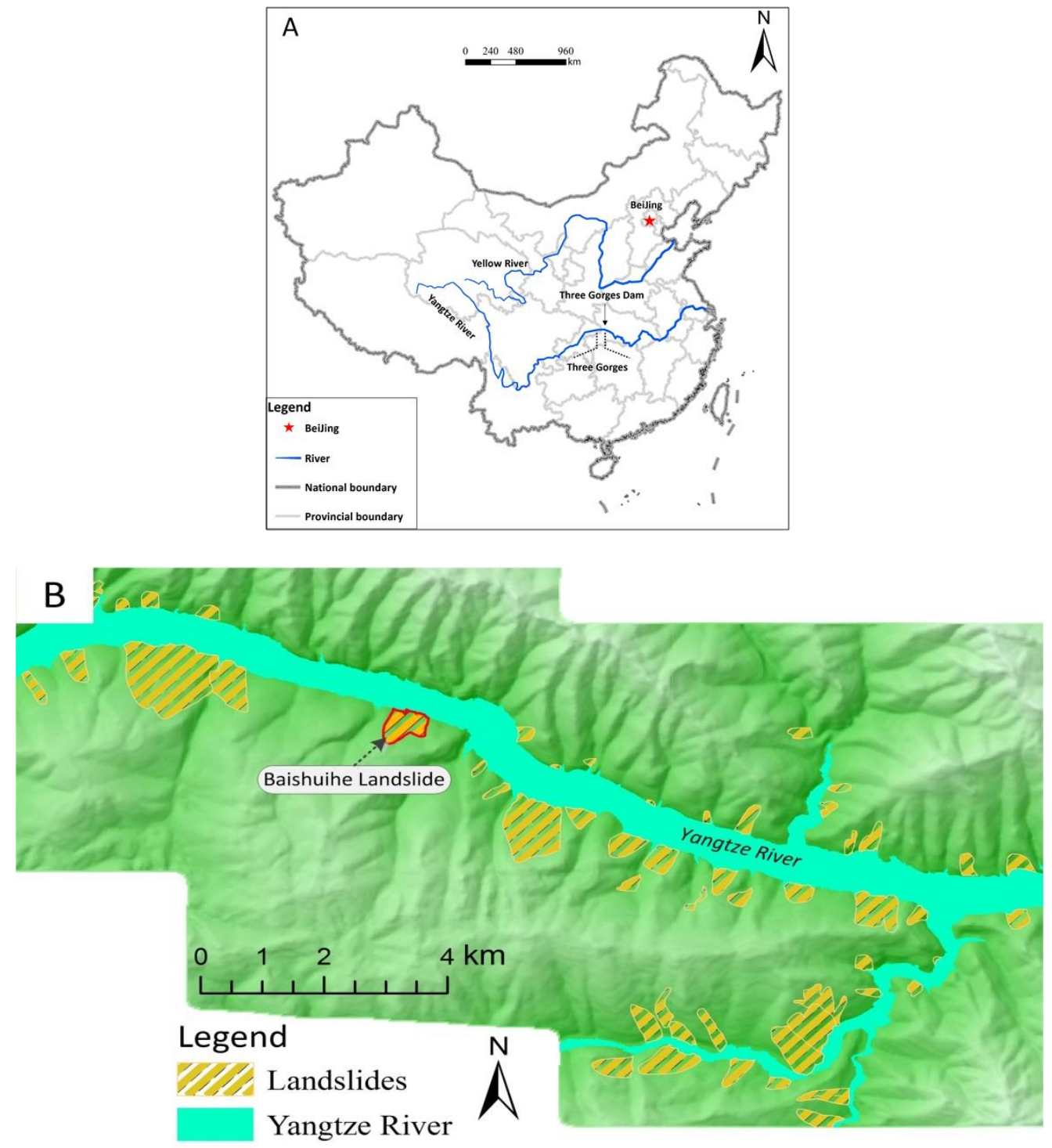

Figure 1. Location of the Three Gorges Dam and the Baishuihe Landslide in China (A) Map of China, (B) Map Showing Location of Baishuihe Landslide 

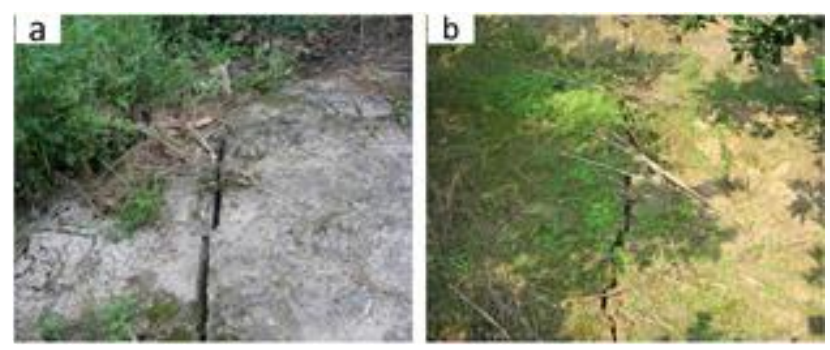

Figure2.Photographs of the Ground Cracks in the Frontal and Middle Part of the Eastern Landslide in September 2005

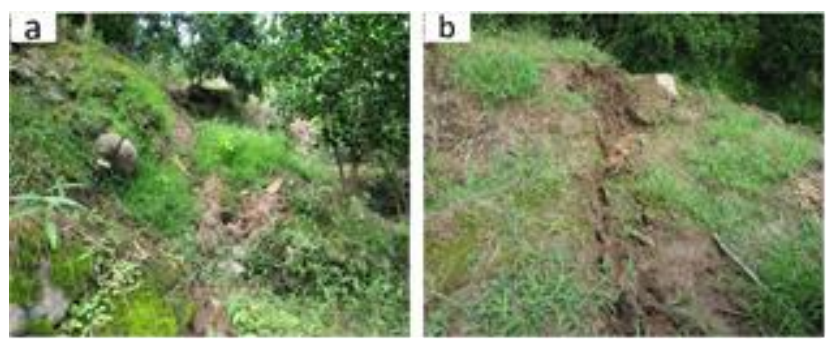

Figure3.Photographs of the Ground Cracks in the Middle Part of the Eastern Landslide in July 2007

\section{RBF-SVM}

SVM modelling is based on a statistical learning theory and the structural risk minimization principle. It involves a training phase with associated input and target output variables. The model issuitablefor nonlinear high-dimensional data modeling problems and can be applied forpredicting the landslide deformation [19]. The pertinent points of the SVM are presented here [20]. Assume that $\left\{x_{i}, y_{i}\right\}(i=1,2, \ldots \ldots, n)$ are training data, where $x$ is a vector of input space that contains the primary influencing factors, $y$ denotesthe landslide displacement. When using the method of Lagrange multipliers $\lambda_{i}$, the cost function can be defined as

$$
L=\frac{1}{2}\|w\|^{2}-\sum_{i=1}^{N} \lambda_{i}\left(y_{i}\left(\left(w \cdot x_{i}\right)+b\right)-1\right)
$$

and

$$
\left\{\begin{array}{l}
\min \frac{1}{2}\left\|w^{2}\right\| \\
\text { s.t. } y_{i}\left(w \square x_{i}+b\right) \geq 1, i=1,2, \ldots, n
\end{array}\right.
$$

where $\|w\|^{2}$ is the Euclidean norm, which determines the orientation of the hyper plane in the feature space, $b$ is the offset of the hyper plane from the origin, and $c$ is a penalty parameter that manages the tradeoff between margin maximization and error minimization.. For a nonseparable case, the positive slack variables $\xi_{i}$ are introduced, and the new optimization problem is defined as 


$$
\left\{\begin{array}{l}
\min _{w, \xi} \frac{1}{2}\left\|w^{2}\right\|+c \sum_{i=1}^{n} \xi_{i} \\
\text { s.t. } y_{i}\left(w \cdot x_{i}+b\right) \geq 1-\xi_{i}, \xi_{i} \geq 0,1,2, \ldots, n
\end{array}\right.
$$

In addition, selection of the kernel functions largelyinfluences the prediction accuracy of SVMs.Following the methods of Bui et al. in [21], an RBF was applied as the kernel function in our study, and this function is given byEq. (4), where $\gamma$ is a positive real number. The prediction performance of the RBF-SVM depends on the choice of the regularization parameter $c$ and the kernel width $\gamma$.

$$
K\left(x_{i}, y_{i}\right)=\exp \left(-\left\|x_{i}-y_{i}\right\|^{2} / 2 \gamma^{2}\right)
$$

\section{Landslide Displacement Prediction}

The macroscopic deformation of the Baishuihe landslide indicates that the deformation in the warning zone was much larger than the deformation in the relatively stable zone. In the warning zone, the deformation in the middle and lower parts was more obvious than the deformation in the upper, especially after the high water level impoundment of the Three Gorges Reservoir beginning in June 2003. Toanalyze the deformation tendency of the Baishuihe landslide, monitoring was performed to provide an early warning spanning approximately 5 years, from January 2004 to May 2008. The schematic diagram of monitoring arrangement in Baishuihe landslide was shown in [2]. There are six GPS deformation monitoring points layout in the landslide surface, which were installed along three longitudinal axes: I, II and III. Locations of the six GPS monitoring points were given in Table 1. Figure 4 shows the monitoring data of landslide accumulative displacement at six monitoring points.

Table 1. Locations of the Six GPS Monitoring Points in the Warning Zone of Baishuihe Landslide

\begin{tabular}{lll}
\hline No. & Elevation $(\mathrm{m})$ & Locations \\
\hline ZG93 & 214.55 & North east \\
ZG118 & 209.26 & Middle and lower \\
DX-01 & 216.16 & North east \\
DX-02 & 187.61 & North east \\
DX-03 & 189.52 & North east \\
DX-04 & 192.63 & North west \\
\hline
\end{tabular}




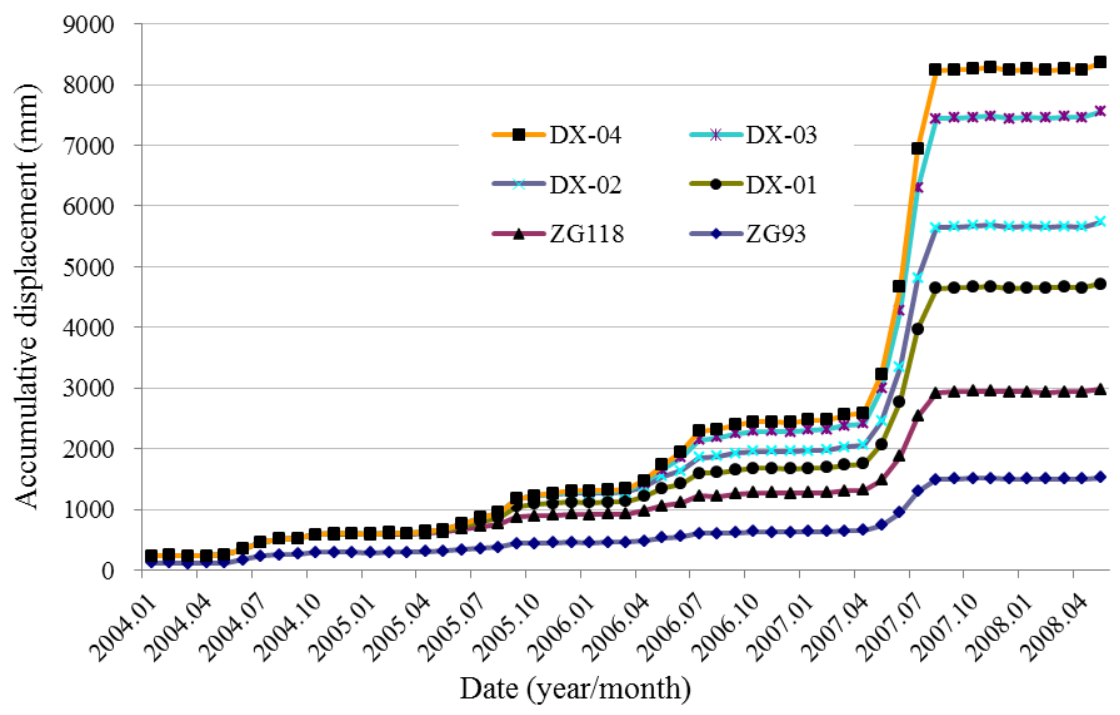

Figure 4. Cumulative Displacement Versus Time at SixGPS Monitoring Points

GPS monitoring point ZG118 was located in middle and lower part of the warning zone. The monitoring results from GPS point ZG118 onthe Baishuihe landslide from 2004 to 2008 were consistent with the observed ground deformation, including ground cracks. Therefore, the monitoring data oflandslide accumulative displacement at ZG118 monitoring point is selected as a case study. Based on the monitoring results and field macroscopic deformation observations, the plot of cumulative displacement versus time at GPS monitoring point ZG118 indicates a clear, continuous increase with a step-like evolution during the monitoring period. The sharp increase in cumulative displacement may have been influenced by the reservoir level and groundwater level fluctuations and the rainy season in the area from May to September of each year. The larger deformation occurred during the rainy season and then returned to a pattern of a slow deformation with a constant speed after the rainy season, particularly after precipitation (Figure 5). The landslide was active during seasonal precipitation or reservoir level and groundwater level fluctuations, particularly when the reservoir level and groundwater level drawdown (Figure 6 and Figure 7). The displacement rate displays a positive correlation with the periodic precipitation and a negative correction with the variationsin the reservoir level and groundwater level. 


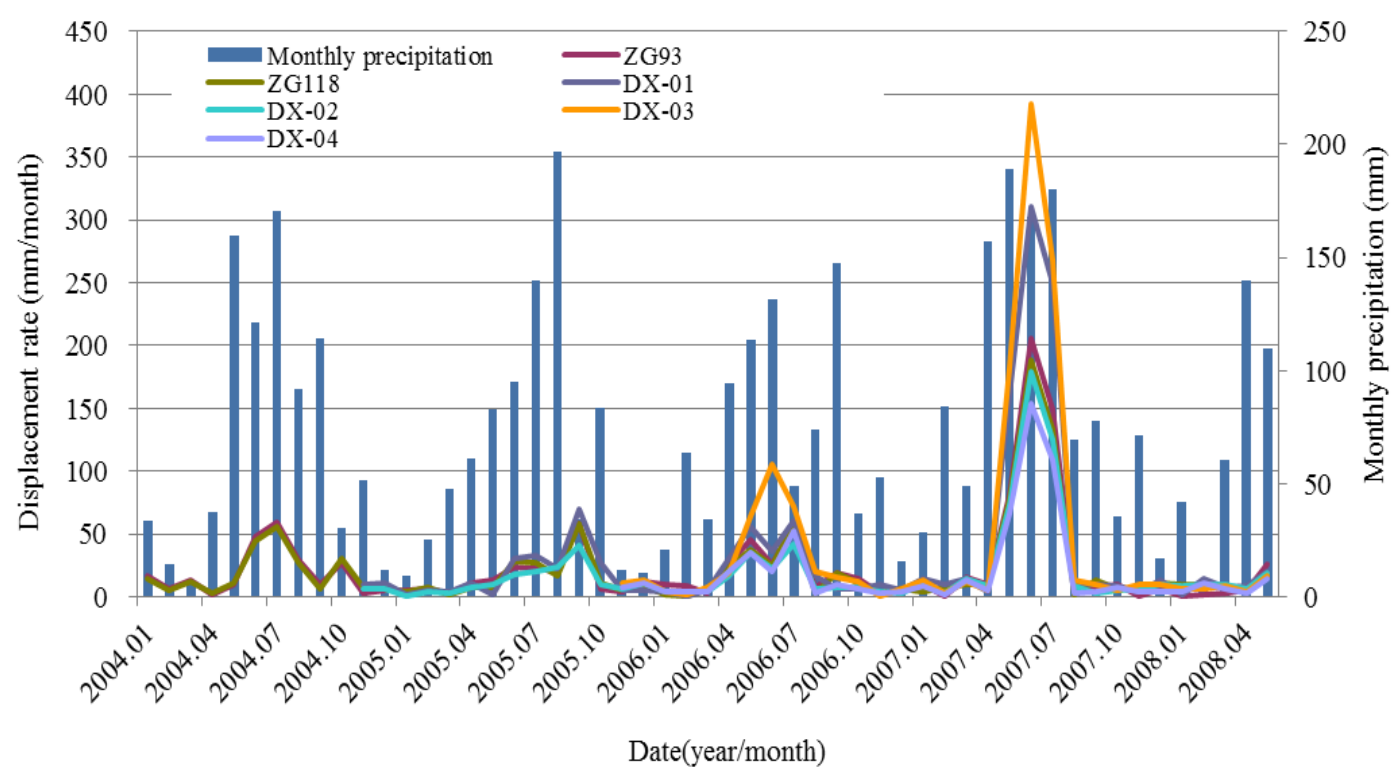

Figure 5.Displacement Rate Versus Time at GPS Monitoring Points.Monthly Accumulative Precipitation in the Three Gorges Reservoir are also Shown

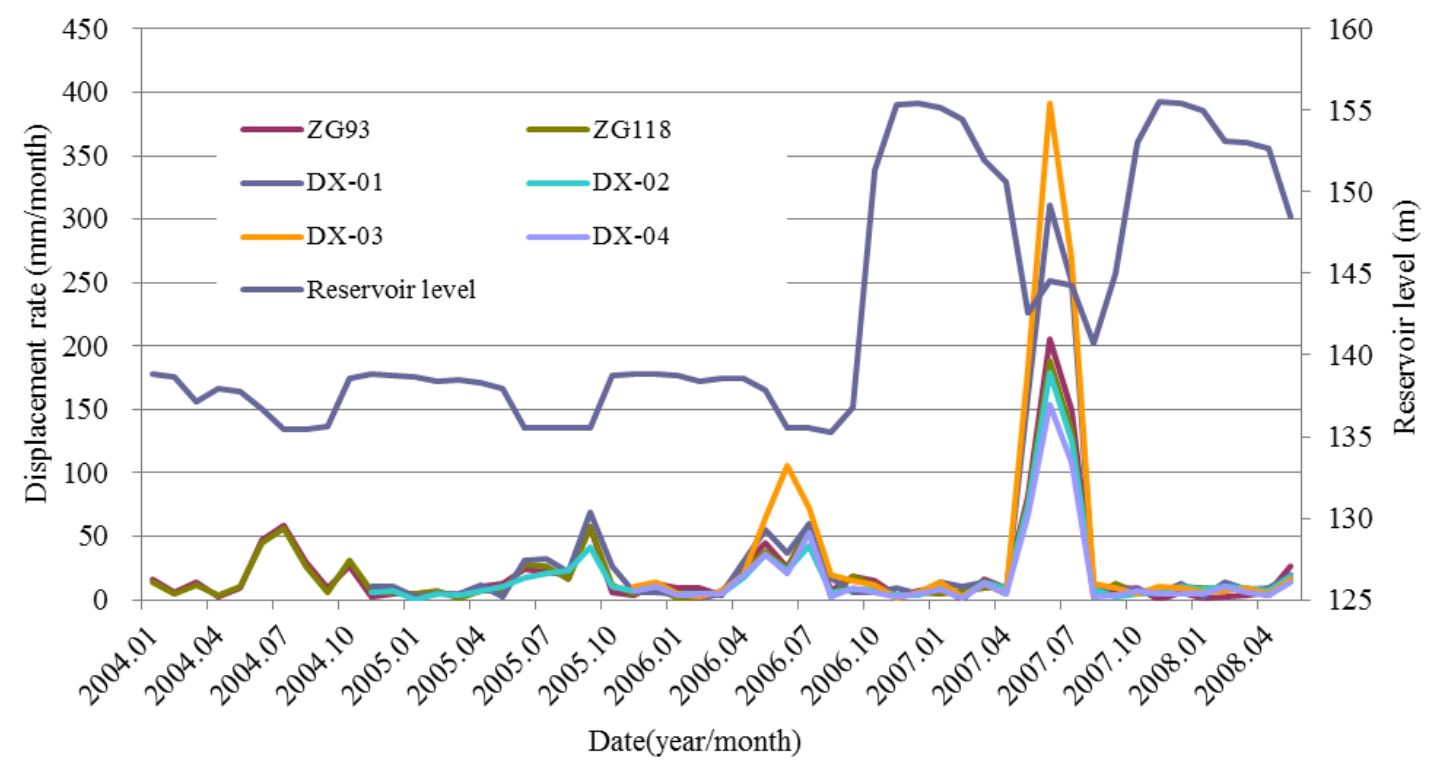

Figure 6. Displacement Rate Versus Time at GPS Monitoring Points.Monthly Reservoir Level Fluctuations in the Three Gorges Reservoir are also Shown 


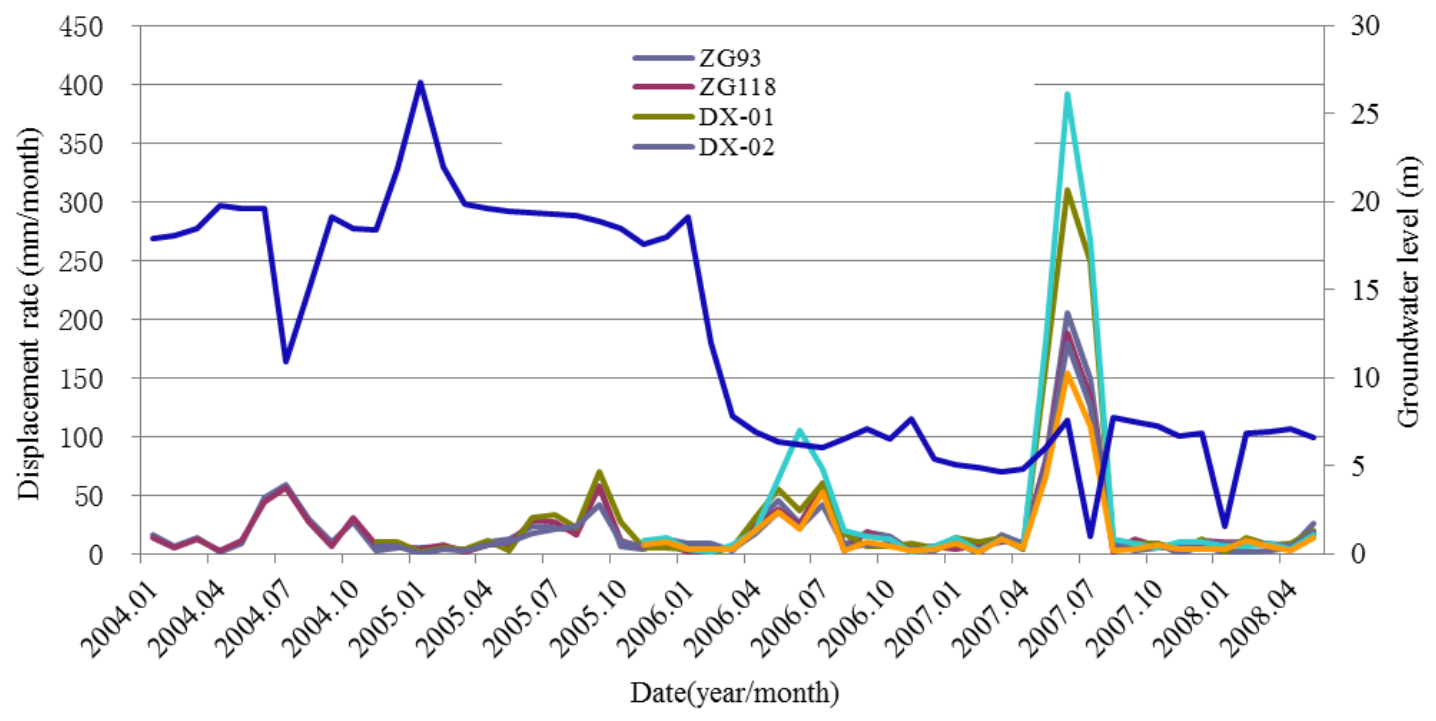

Figure 7. Displacement Rate Versus Time at GPS Monitoring Points. Monthly Groundwater Level Fluctuations in the Three Gorges Reservoir are also Shown

A landslide is a nonlinear, dynamic, and uncertain system controlled and influenced by geologic, topographic, and other conditioning factors. Correlatingthe deformation of an active landslide with environmental factors is significant in an understandingof the complexity and random characteristics of landslide displacement. Landslide evolution and deformation in the Three Gorges Reservoir is closely related to the seasonal precipitation, reservoir level and groundwater level fluctuations. There are 53 groups of measurement data from the period January 2004 to May 2008.Each time step represents one month. There is no exact mathematical rule to determine the required minimum size of training samples and test samples. But some suggestions for the portions ofthese samples are given in the literature [22]. Considering these suggestions, $80 \%$ of the measurement data were randomly selected as the training samples for training models, and the remaining $20 \%$ were used for validation testing.

The displacement at the GPS monitoring points displays a periodic fluctuation that is strongly correlated to the reservoir level and groundwater level fluctuationsand seasonal precipitation. The displacement prediction of landslide was used to develop causal relationships between the observed displacement and the seasonal precipitation and reservoir level and groundwater level fluctuations and was then used to predict the future landslide deformation. Based on the characteristics of the periodic displacement, six primary driving factors were extracted from the precipitation, reservoir level, and groundwater level monitoring data, including the cumulative precipitation during the current month, maximum daily precipitation during the current month, average reservoir level during the current month, cumulative incrementsand decrements inthe reservoir level during the current month, average groundwater level during the current month, and cumulative incrementsand decrements inthe groundwater level during the current month.

The displacement at GPS monitoring point ZG118 was used to create the prediction model. From the dataset, 39 groups of the monitoring data were selected for training of the two-class SVM, and the remaining 14 groups were used for validation testing. 
TheSVM model utilizes a kernel function to map data from the original feature space to a high-dimensional space. Using a SVM, a nonlinear landslide system can be converted into a linear landslide system. Three function types based on SVM model were employed as the kernel functions to predict the landslide displacement, including polynomial function, sigmoid function, and RBF. Primary landslide influencing factors were used as independent input variables of SVM model. Optimal parameter search on SVM plays a crucial role in building a landslide prediction model. The function yielding the highest accuracy was selected as the optimal parameters.Three parameters, $c, \varepsilon$ and $\gamma$, must be carefully predetermined to establish an efficient SVM model. cdetermines the trade-offs between the minimization of the fitting error and the minimization of the model complexity, $\varepsilon$ is the regression precision, and $\gamma$ is the bandwidth of the kernel function. Figure 8, Figure 9, and Figure 10 is the choice of optimal parameters $c, \varepsilon$ and $\gamma$ for sigmoid function, polynomial function, and RBF, respectively.

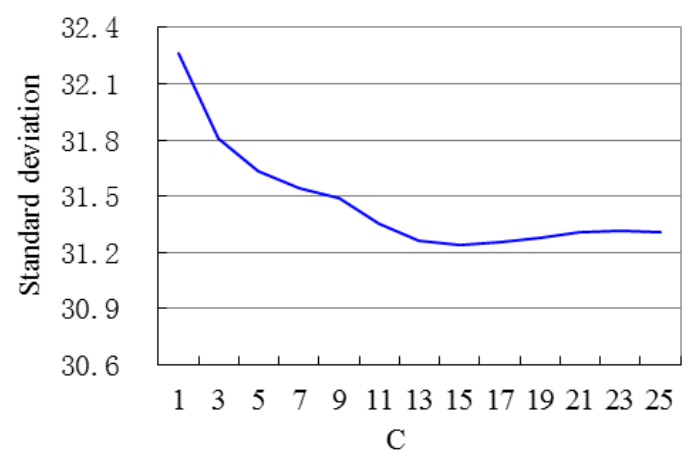

(a) TheStandard Deviation of theModel Where $\varepsilon$ and $\gamma$ were Specified as Constants

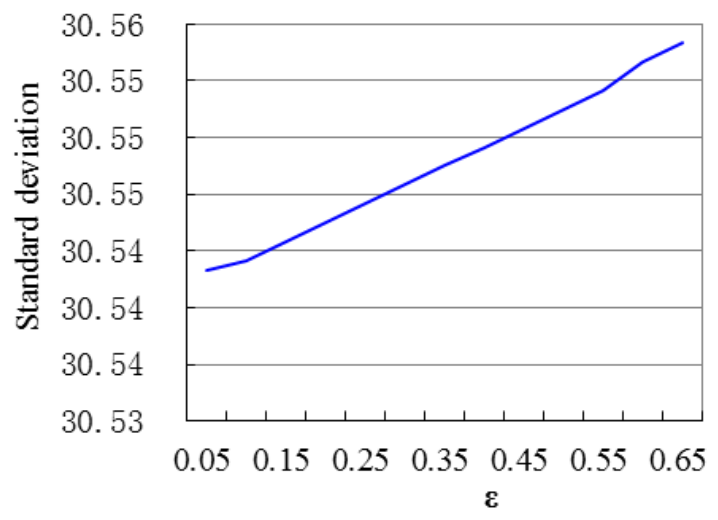

(b) TheStandard Deviation of the Model Where ${ }^{c}$ and ${ }^{\gamma}$ were Specified as Constants 
International Journal of u-and e-Services, Science and Technology Vol.7, No.5 (2014)

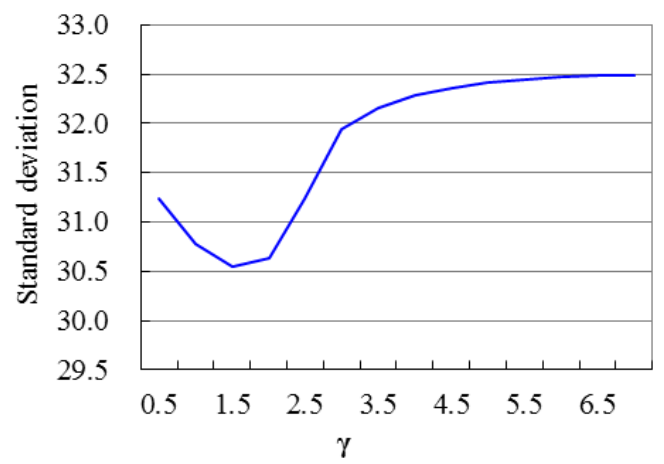

(c) TheStandard Deviation of theModel Where ${ }^{c}$ and $\varepsilon$ were Specified as Constants

Figure 8. Choice of Optimal Parameters $c, \varepsilon$ and $\gamma$ for Sigmoid Function Based on SVM Model

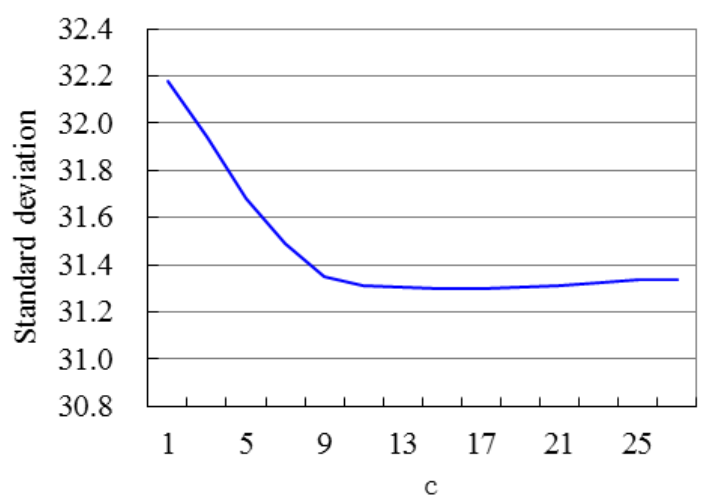

(a) TheStandard Deviation of theModel Where ${ }^{\varepsilon}$ and ${ }^{\gamma}$ were Specified as Constants

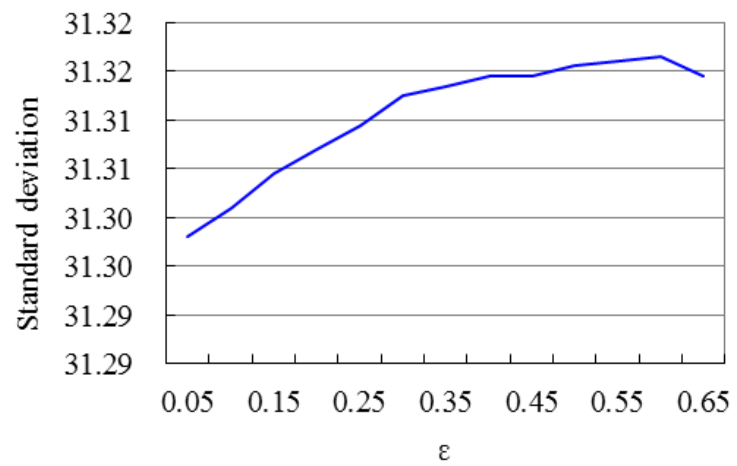

(b) TheStandard Deviation of the Model Where ${ }^{c}$ and ${ }^{\gamma}$ were Specified as Constants 


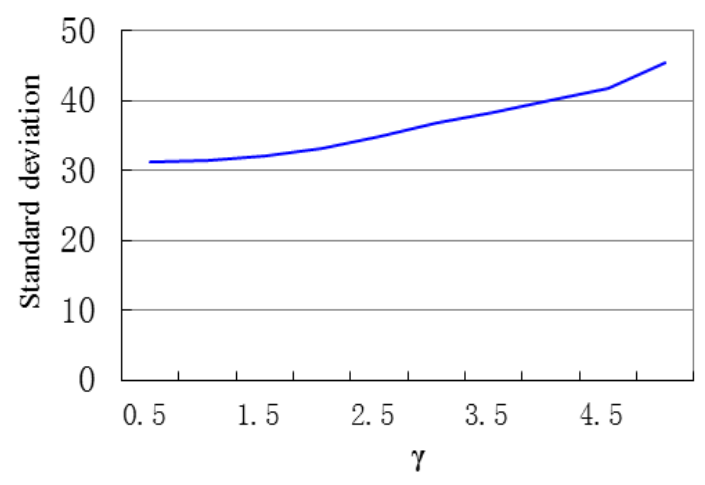

(c) TheStandard Deviation of theModel Where ${ }^{c}$ and $\varepsilon$ were Specified as Constants

Figure 9. Choice of Optimal Parameters $c, \varepsilon$ and $\gamma$ for Polynomial Function Based on SVM Model

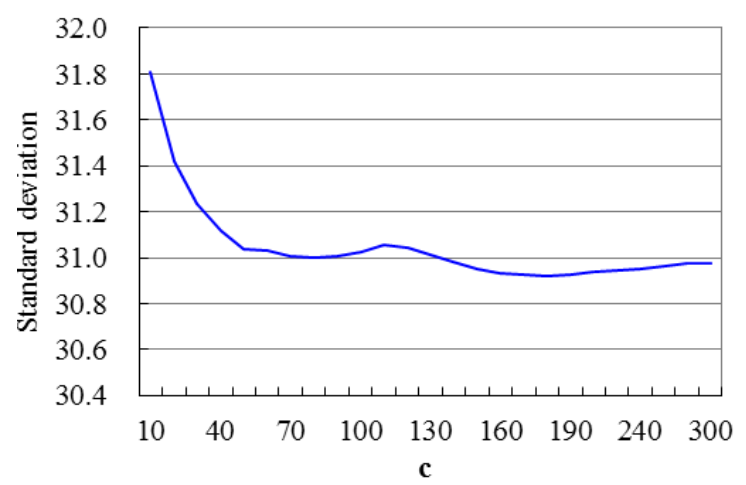

(a) TheStandard Deviation of theModel Where ${ }^{\varepsilon}$ and ${ }^{\gamma}$ were Specified as Constants

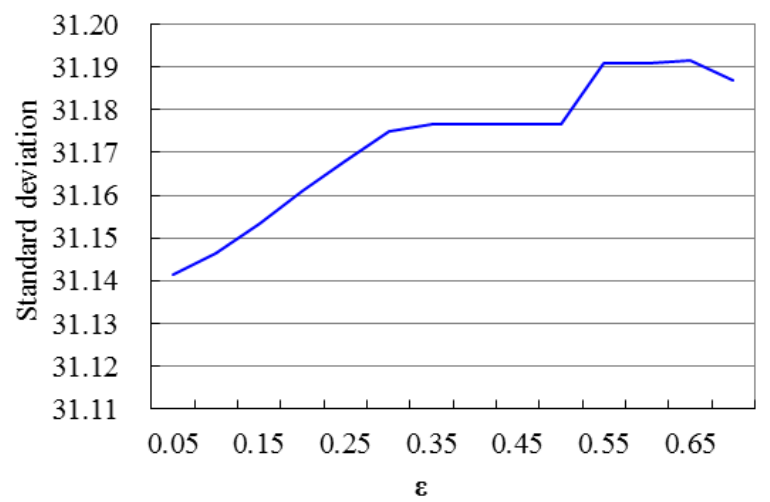

(b) TheStandard Deviation of the Model Where ${ }^{c}$ and ${ }^{\gamma}$ were Specified as Constants 


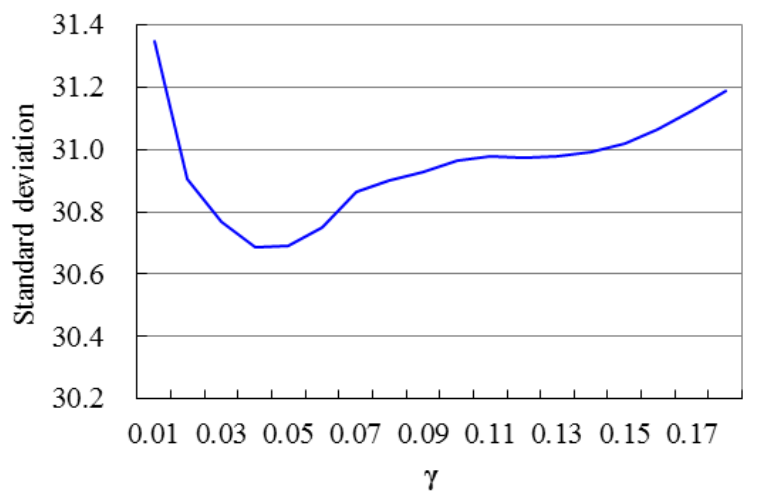

(c) TheStandard Deviation of theModel Where ${ }^{c}$ and $\varepsilon$ were Specified as Constants

\section{Figure 10. Choice of Optimal Parameters ${ }^{c},{ }^{\varepsilon}$ and ${ }^{\gamma}$ for RBF based on SVM Model}

Using the whole 53 groups of monitoring data at GPS monitoring point ZG118 from the period January 2004 to May 2008 as input variables, the six landslide influencing factors were used as independent variables to predict the displacement by three kernel function types including polynomial function, sigmoid function, and RBF based on SVM model. The optimal parameters for the three kernel functions based on SVM model and the corresponding absolute errors were listed in Table 2. RBF-SVM model possesses higher accuracy, with a minimum absolute error of $10.716 \mathrm{~mm}$. Therefore, displacement at GPS monitoring point ZG118 was assessed using a RBF-SVM model in the MATLAB 2010b software. The aim of the RBF-SVMmodel was to optimize the SVM prediction accuracy by solving the SVM model selection by estimating the best values of the regularization and kernel parameters. Using the training data, the RBF was adopted as the kernel function, and a better combination of $c, \varepsilon$ and $\gamma$ for the SVM was searched for. The values of these parameters were set to 170, 0.05 and 0.04, respectively. The RBF-SVM model with the optimal parameters was trained and then used to predict the displacement at monitoring point ZG118. Using the 14 groups of monitoring data as testing samples, the corresponding prediction results of the displacement are listed in Tables 3. Compared with the sigmoid function and polynomial function based on SVM model, the RBF-SVM model with optimal parameters obtained better prediction results, with maximum, minimum, and mean absolute errors of $9.84 \mathrm{~mm}, 0.47 \mathrm{~mm}$, and $4.26 \mathrm{~mm}$, respectively.

Table 2. Optimal Parameters for Three Types Kernel Functions of SVM Model

\begin{tabular}{lllll}
\hline Kernel function & $c$ & $\varepsilon$ & $\gamma$ & Absolute error $(\mathrm{mm})$ \\
\hline RBF & 170 & 0.05 & 0.04 & 10.716 \\
Polynomials & 17 & 0.05 & 0.50 & 10.814 \\
Sigmoid & 15 & 0.05 & 1.50 & 10.949 \\
\hline
\end{tabular}


Table 3. Prediction Results and Accuracies of the Displacement at GPS Monitoring Point ZG118 Using Testing Data

\begin{tabular}{llll}
\hline $\begin{array}{l}\text { Date } \\
\text { (year/month) }\end{array}$ & $\begin{array}{l}\text { Measured } \\
\text { value }(\mathrm{mm})\end{array}$ & $\begin{array}{l}\text { Prediction value } \\
(\mathrm{mm})\end{array}$ & $\begin{array}{l}\text { Absolute error } \\
(\mathrm{mm})\end{array}$ \\
\hline $2004 / 04$ & 3 & 9.24 & 6.24 \\
$2005 / 01$ & 4.1 & 4.57 & 0.47 \\
$2005 / 03$ & 1.4 & 8.55 & 7.15 \\
$2005 / 04$ & 7.1 & 11.02 & 3.92 \\
$2005 / 10$ & 11.2 & 10.26 & 0.94 \\
$2006 / 03$ & 6.7 & 13.28 & 6.58 \\
$2006 / 04$ & 23.4 & 15.75 & 7.65 \\
$2006 / 11$ & 3.2 & 4.17 & 0.97 \\
$2006 / 12$ & 6.1 & 4.07 & 2.03 \\
$2007 / 03$ & 9.5 & 7.13 & 2.37 \\
$2007 / 10$ & 5.8 & 4.88 & 0.92 \\
$2007 / 12$ & 10.8 & 3.06 & 7.74 \\
$2008 / 01$ & 9.4 & 6.53 & 2.87 \\
$2008 / 04$ & 3.6 & 13.44 & 9.84 \\
\hline
\end{tabular}

\section{Conclusions}

Landslide displacement prediction is of great significance for preventing landslides and reducingthe risk in the Three Gorges Reservoir area. This paper presents the prediction of landslide displacement of the Baishuihe landslide using 5 years of monitoring data and RBF-SVM model. The cumulative displacement versus time shows a step-like pattern that is related to the precipitation, reservoir level and groundwater level fluctuations. Precipitation is a major driving factor and has a positive correlation with the displacement rate. The landslide deformation is larger during reservoir level and groundwater level fluctuations, particularly when the reservoir level and groundwater level declines. Based on the mechanism and characteristics of the landslide deformation, six conditioning factors-related precipitation and reservoir level and groundwater level were selected as independent prediction variables in a RBF-SVM model to predict the landslide displacement, with the maximum and minimum absolute error values of 9.84 and $0.47 \mathrm{~mm}$, respectively. Using the whole 53 groups of monitoring data, the prediction results demonstrate that the proposed RBF-SVM model has higher prediction accuracy than does the sigmoid function and polynomial kernel function based on SVM model, with the absolute error of $10.716 \mathrm{~mm}$. The prediction results agree with the observed values. This study may provide useful information to engineers and planners involved in investigating landslide hazards. 


\section{Acknowledgments}

This study was jointly supported by the NSFC (41271455/D0108) and Open Research Fund of State Key Laboratory of Information Engineering in Surveying, Mapping and Remote Sensing (13S01). The authors would like to thank the members of the Administration ofPrevention and Control of Geo-Hazards in the Three GorgesReservoir of China for their assistance in data collection.

\section{References}

[1] X.L.Wu, R.Q.Niu, F.Ren and L.Peng, "Landslide Susceptibility Mapping Using Rough Sets and BackPropagation Neural Networks in the Three Gorges, China", Environmental Earth Sciences, vol. 70, no. 3,(2013),pp. 1307-1318.

[2] C.Lian, Z.Zeng, W.Yao and H.Tang, "Displacement Prediction Model of Landslide based on a Modified Ensemble Empirical Mode Decomposition and Extreme Learning Machine", Environmental Earth Sciencevol. 66, no. 2,(2013), pp.759-771.

[3] M.Xia, G.M.Ren and X.L.Ma, "Deformation and Mechanism of Landslide Influenced by the Effects of Reservoir Water and Rainfall, Three Gorges, China", Natural Hazards,vol. 68, no. 2,(2013), pp. 467-482.

[4] J.G.Liu, P.J.Mason, N.Clerici, S.Chen, A.Davis, F.Miao and H.Deng, L.Liang, "Landslide Hazard Assessment in the Three Gorges Area of the Yangtze River Using ASTER Imagery: Zigui-Badong", Geomorphology, vol. 61, no. 1,(2004), pp. 171-187.

[5] X.Li, J.Kong and Z.Wang, "Landslide Displacement Prediction Based on Combining Method with Optimal Weight", Natual Hazards, vol. 61, no. 2, (2012), pp. 635-646.

[6] Dinesh Bisht, Shilpa Jain and M. Mohan Raju, "Prediction of Water Table Elevation Fluctuation through Fuzzy Logic \& Artificial Neural Networks", International Journal of Advanced Science and Technology, vol. 51, no. 7,(2013), pp. 107-120.

[7] W.J.Randall, "Regression Models for Estimating Coseismic Landslide Displacement",engineering geology, vol.91, no. 2, (2007), pp. 209-218.

[8] Y. Lv and H. Liu, "Prediction of Landslide Displacement Using Grey and Artificial Neural Network Theories", Advanced Science Letters, vol. 11, no. 1, (2012), pp. 511-514.

[9] H. Chen and Z. Zeng, "Deformation Prediction of Landslide Based on Improved Back-Propagation Neural Network", Cognitive Computation, vol. 5, no. 1, (2013), pp. 55-62.

[10] J. Du, K. Yin and S. Lacasse, "Displacement Prediction in Colluvial Landslides, Three Gorges Reservoir, China", Landslides, vol. 10, no. 2, (2013), pp. 203-218.

[11] X. Wu, V. Kumar, Q. J. Ross, J. Ghosh, Q. Yang, H. Motoda, et al., "Top 10 Algorithms in Data Mining”, Knowledge and Information Systems, vol.14, no. 1, (2008), pp. 1-37.

[12] H. Dong, H. Fu, W. Feng and Z. Deng, "Landslide Dexpertisplacement Prediction Based on Takens Theory and SVM", China Journal of Highway and Transportation, vol. 20, no. 5, (2007), pp. 13-18.

[13] C. Zhu and G. Hu, "Time Series Prediction of Landslide Displacement Using SVM Model: Application to Baishuihe Landslide in Three Gorges Reservoir Area, China”, Applied Mechanics and Materials, vol. 239, (2013), pp. 1413-1420.

[14] N. Micheletti, L. Foresti, M. Kanevski, A. Pedrazzini and M. Jaboyedoff, "Landslide Susceptibility Mapping Using Adaptive Support Vector Machines and Feature Selection”, Geophysical Research Abstracts, vol.13, (2011).

[15] J. H. Min and Y. C. Lee, "Bankruptcy Prediction Using Support Vector Machine with Optimal Choice of Kernel Function Parameters", Expert Systems with Applications, vol. 28, no. 4, (2005), pp. 603-614.

[16] C. H. Wu, G. H. Tzeng, Y. J. Goo and W. C. Fand, "A Real-Valued Genetic Algorithm to Optimize the Parameters of Support Vector Machine for Predicting Bankruptcy", Expert Systems with Applications, vol. 32, no. 2, (2007), pp. 397-408.

[17] A. Khazaee and A. Ebrahimzadeh, "Classification of Electrocardiogram Signals with Support Vector Machines and Genetic Algorithms Using Power Spectral Features", Biomedical Signal Processing and Control, vol. 5, no. 4, (2010), pp. 252-263.

[18] I. Ilhan and G. Tezel, "A Genetic Algorithm-Support Vector Machine Method with Parameter Optimization for Selecting the Tag SNPs", Journal of Biomedical Informatics, vol. 46, no. 2, (2013), pp. 328-340.

[19] V. Vapnik, “The Nature of Statistical Learning Theory”, New York, Springer-Verlag, (1995).

[20] M. J. Abdi and D. Giveki, "Automatic Detection of Erythemato-Squamous Diseases Using PSO-SVM based on Association Rules", Engineering Applications of Artificial Intelligence, vol. 26, no. 1, (2013), pp. 603-608. 
[21] D. T. Bui, B. Pradhan, O. Lofman and I. Revhaug, "Landslide Susceptibility Assessment in Vietnam Using Support Vector Machines, Decision Tree and Naïve Bayes Models", Mathematical Problems in Engineering, (2012).

[22] B. Pradhan and S. Lee, "Landslide Susceptibility Assessment and Factor Effect Analysis: Backpropagation Artificial Neural Networks and Their Comparison with Frequency Ratio and Bivariate Logistic Regression Modeling”, Environmental Modelling \& Software, vol. 25, no. 6, (2010), pp. 747-759.

\section{Authors}

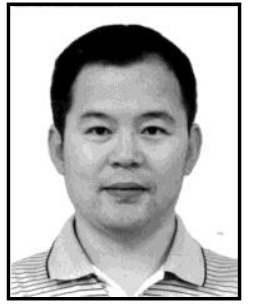

Fu Ren, he received the Ph.D. degree in cartography and geographic information engineering from Wuhan University, China, in 2006. He is currently an associate professor at the School of Resource and Environmental Sciences, Wuhan University, China. His research interests include carto-linguistics, online dynamic thematic cartography, theoretical and experimental research on geospatial information.

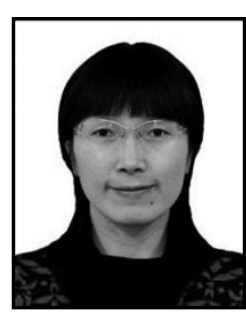

Xueling Wu, she received the Ph.D. degree in cartography and geographic information engineering from Wuhan University, China, in 2009. She is currently an associate professor at the Institute of Geophysics\&Geomatics, China University of Geosciences, China. Her research interests include Geo-science spatial analysis and landslide hazard predication. 
International Journal of $u$-and e-Services, Science and Technology Vol.7, No.5 (2014) 